\title{
GOVERNANÇA COOPERATIVA: AS FUNÇÕES DE FISCALIZAÇÃO E CONTROLE EM COOPERATIVAS DE CRÉDITO NO BRASIL
}

\section{COOPERATIVE GOVERNANCE: THE ROLE OF SUPERVISION AND CONT ROL IN CREDIT COOPERATIVE IN BRAZIL}

\author{
MARIA DE FÁTIMA CAVALCANTE TOSINI \\ Banco Central do Brasil \\ E-mail: fatima.tosini@bcb.gov.br
}

\author{
ALEXANDRE MARTINS BASTOS \\ Banco Central do Brasil \\ E-mail: alexandre.bastos@bcb.gov.br
}

\begin{abstract}
Resumo
O objetivo do artigo é analisar as funções de fiscalização e controle nas cooperativas de crédito como elementos necessários às boas práticas de governança nessas organizações, e propor instrumentos e condições para que, sem impactos significativos em custos e respeitadas características próprias de cada cooperativa, a capacidade de controle e acompanhamento dos agentes envolvidos no processo seja desenvolvida. A fiscalização e o controle desempenham papel fundamental na governança dessas entidades, permitindo aos seus associados e dirigentes avaliar o alcance dos objetivos sociais e corrigir os rumos estratégicos, assumindo, em conseqüência, papel relevante para a continuidade dessas organizações. 0 artigo apresenta resultado de pesquisa institucional, realizada pelo Banco Central no universo das cooperativas de crédito singulares e em amostragem de seus associados, com o objetivo de avaliar o estado da arte em relação às suas principais práticas de governança. As respostas fornecidas por 1199 cooperativas e por 420 associados foram cotejadas e analisadas frente às funções de fiscalização e controle nas cooperativas. Com base nessas análises são propostas reflexões e direcionamentos para a melhoria de sua governança.
\end{abstract}

Palavras-chave: cooperativa de crédito, governança, fiscalização, controle.

\section{Abstract}

The article analyzes supervision and control functions in financial cooperatives as necessary elements to good governance practices in such organizations, suggesting instruments and conditions in a way to enable, with no significant cost impacts and respected the individual characteristics of each financial cooperative, a development in the controlling and monitoring ability of agents involved in this process. Supervision and control have a fundamental role in governance of such institutions, allowing their members and officials to assess the reach of corporate goals and refine strategic goals assuming, in consequence, a relevant role in the continuity of financial cooperatives. The article discloses the result of an institutional survey, conducted by the Central Bank of Brazil, in both the universe of single financial cooperatives and a sample of their members, with the purpose of compiling and understanding their main governance practices. Answers provided by 1199 financial cooperatives and 420 members were compared and analyzed vis-à-vis the functions of supervision and control in financial cooperatives. Based on such analyses, reflections and directions are suggested to improve financial cooperative governance.

Key-words: Financial cooperative, governance, supervision, control. 


\section{INTRODUÇÃO}

O interesse em torno da governança corporativa tem crescido nos últimos anos, tanto para o público especializado e empresas de capital aberto quanto para demais organizações em que há a separação da figura do proprietário e do gestor dos negócios.

O movimento pela governança corporativa ganhou força em meados da década iniciada em 1980 nos Estados Unidos. Os grandes investidores institucionais passaram a se mobilizar contra algumas corporações que eram administradas de maneira irregular, em detrimento dos acionistas. Esse movimento foi se expandindo pelo mundo, chegando à Inglaterra, inicialmente, se estendendo pelo restante da Europa, e na última década, ao Brasil.

A denominação governança corporativa, do original em inglês corporate governance, refere-se aos arranjos institucionais que regem as relações entre acionistas (ou outros grupos) e as administrações das empresas (LETHBRIDGE, 1997). Embora o termo tenha se firmado nas disciplinas econômicas como exclusivo das relações empresariais, sua compreensão deve transcender ao universo das empresas de mercado, podendo vir a ser utilizado de forma mais ampla para designar os diversos arranjos necessários à gestão de uma organização, seja ela pública, privada, ou comunitária, com ou sem finalidade lucrativa.

Quando um investidor procura maior influência sobre a atuação das empresas nas quais têm participação no controle, está buscando implementar práticas de governança corporativa de modo a assegurar que os agentes (empresas) atendam aquilo que, como investidor, delas se espera. Da mesma forma, quando uma comunidade pressiona um poder constituído com vistas a obter 0 atendimento de uma necessidade específica, tal como a construção de uma via expressa, a instalação de um posto de saúde, a maior fiscalização a um setor econômico, também está buscando assegurar que os agentes implementem seus anseios.

Governança Corporativa remete ao governo da organização, à articulação do poder entre as partes com direitos de propriedade e controle e os responsáveis pela gestão, não se limitando às questões de verificação de procedimentos contábeis, auditorias ou à remuneração dos gestores. Envolve algo maior, as relações entre controladores, acionistas minoritários, gestores, mercado de capitais e financiadores em geral, bem como o grupo das denominadas partes interessadas (stakeholders), formada pelos empregados, clientes e fornecedores, órgãos reguladores e a própria sociedade.

O objetivo do artigo é analisar as funções de fiscalização e controle nas cooperativas de crédito como elementos necessários às boas práticas de governança nessas organizações, e propor instrumentos e condições para que, sem impactos significativos em custos e respeitadas características próprias de cada cooperativa, a capacidade de controle e acompanhamento dos agentes envolvidos no processo sej a desenvolvida.

Os conceitos teóricos utilizados no artigo para fundamentar a discussão são derivados da teoria da agência, explorando aspectos relativos à separação entre propriedade e gestão (conflitos de agência) e riscos de comportamento - risco moral (moral harzard) e o efeito carona (free rider). Além dos aspectos teóricos, há discussão sobre o ambiente institucional das cooperativas de crédito, especialmente com relação a aspectos legais ligados à fiscalização e controle.

0 trabalho está dividido em cinco partes, além dessa introdução. A primeira trata de conceitos referentes a governança em instituições financeiras e em cooperativas de crédito. A segunda apresenta a metodologia da pesquisa. A terceira apresenta propostas de instrumentos de fiscalização e controle para melhorar a estrutura de governança nas 
cooperativas de crédito. Na quarta parte, com base no diagnóstico obtido na pesquisa junto às cooperativas e seus associados, são discutidas as perspectivas das cooperativas de crédito brasileiras adotarem os instrumentos propostos e, por fim, as considerações finais.

\section{PRINCIPAIS CONCEITOS DE GOVERNANÇA APLICADOS INSTITUIÇÕES FINANCEIRAS E COOPERATIVAS DE CRÉDITO}

De acordo com Lethbridge (1997), é possível distinguir dois tipos extremos de controle corporativo: shareholder, no qual a obrigação primordial dos administradores é agir em nome dos interesses dos acionistas; e stakeholder, onde, além dos acionistas, um conjunto mais amplo de interesses deve ser contemplado pela ação e pelos resultados da corporação.

No controle shareholder, do contexto anglo-saxão, a ênfase é dada ao acionista e o objetivo principal é a obtenção de lucro. O acerto das estratégias adotadas é avaliado primordialmente pelo mercado, onde as análises dos investidores são refletidas nas oscilações dos mercados secundários de títulos.

Na perspectiva stakeholder, base do ambiente nipo-germânico, os interesses dos acionistas buscam ser equilibrados aos de outros grupos que são impactados pelas suas atividades, como empregados, fornecedores, clientes e a comunidade.

Analisando esses modelos de governança e considerando as características das cooperativas de crédito de pertencerem ao setor financeiro - setor altamente exposto a risco sistêmico, ou seja, o risco da quebra de instituição financeira contaminar todo o sistema - e, ao mesmo tempo, não pertencerem ao mercado acionário, portanto, não suj eitas ao escrutínio dos investidores, e serem organizações associativas, entende-se que o melhor sistema de governança para essas instituições é o stakeholder.

Portanto, as boas práticas de governança nas cooperativas de crédito devem abranger suas relações com os diversos agentes diretamente ligadas a ela e com os demais agentes econômicos que também são partes interessadas. Deve abranger as políticas, os procedimentos, as sanções, prevenções, o processo adotado nas tomadas de decisões, a estrutura legal, os organismos governamentais e, adicionalmente, os valores, os princípios e a cultura desenvolvidos para proteger os interesses dos diferentes stakeholders ligados à organização (PARADIS, 2001).

A discussão sobre a importância da fiscalização e controle na estrutura de governança passa por alguns conceitos teóricos importantes tratados na Teoria da Agência - problemas de agência e de comportamento dos agentes. Embora os comportamentos sejam únicos, não passíveis de quantificação, portanto incertos (WILLIAMSON, 1987), são operacionalizados por meio dos conceitos de risco moral, seleção adversa e efeito carona (free rider).

Os problemas de agência surgem quando um ou mais indivíduos, denominados "principais", contratam outros indivíduos ou grupo de indivíduos, denominados "agentes", para realização de um serviço que prescinde da outorga pelos "principais" aos "agentes" de autoridade para tomada de decisão, em seu nome e interesse. 0 problema de agência passa a existir no momento em que o agente, que deve sempre atuar no melhor interesse do principal, passa a atuar, ao contrário, em seu próprio interesse (J ENSEN; MECKLING, 1976). As tomadas de decisão pelos agentes passam pelo chamado conflito de agência conflito em tomar decisão visando maximizar suas próprias utilidades ou visando maximizar o retorno para os proprietários (principal). 
O risco moral (moral harzard) ocorre quando há probabilidade de comportamento oportunista após um evento contratual (KREPS, 1990). O conceito transmite uma idéia de risco de desvio de comportamento considerado ético, e por isso, risco moral. 0 agente pode, após a contratação, agir de forma diferente de como agiria se fosse o único beneficiário de seus esforços. 0 risco moral surge devido à dificuldade de se assegurar 0 comportamento ético dos agentes econômicos, uma vez que eles têm uma propensão diferente para agir de forma oportunista; não fosse por isto, qualquer comportamento poderia ser governado por regras.

Segundo Desrochers e Fischer (2002), a principal causa de quebra de instituições financeiras decorre de problemas relacionados à governança. Eles identificam duas causas principais. A primeira causa seria de risco moral, definido por eles como o risco de exposição, por exemplo, risco de crédito, risco de taxa de juros, risco de liquidez, riscos assumidos e não contabilizados - off balance. A tomada de decisão pelos dirigentes, sobre o nível de exposição desses riscos, embora sej am próprios da atividade financeira, pode ser no interesse dos acionistas - aumentando a exposição aos riscos de maneira que prejudique os credores (depositantes, poupadores, credores etc.); ou assumindo uma posição mais conservadora, ou seja, com menor alavancagem, dando mais conforto para os credores e menos retorno para os acionistas. Nessa decisão há, portanto, um conflito de interesse entre os credores e acionistas.

Trazendo esse conceito para a realidade das cooperativas de crédito, tem-se a seguinte situação: os credores, em geral, salvo alguns organismos oficiais repassadores de recursos, são os próprios associados. Aparentemente não haveria o risco moral dos dirigentes tomarem decisões favoráveis aos associados em detrimento dos credores uma vez que estes também são associados. O fato de os credores serem também os proprietários da cooperativa tende a reduzir o risco de exposição, mas não o elimina. Por exemplo, entre os associados, há grupos de poupadores e tomadores líquidos de recursos. As decisões na gestão da cooperativa certamente geram conflito de interesse entre esses dois grupos de sócios. Se os dirigentes decidirem por maximizar o retorno para os credores, poderá prejudicar o grupo de tomadores líquidos e vice-versa.

A segunda causa de quebra de instituições financeiras se refere a problemas de agência, que consiste na hipótese do comportamento do dirigente, nas tomadas de decisões, ser favorável à maximização de sua própria utilidade em detrimento do interesse dos associados. Pode-se cair em um equívoco, semelhante ao do risco moral, ao pensar que esse comportamento não existe nas cooperativas de crédito, uma vez que seus dirigentes são também proprietários. Segundo os autores, essa é a principal causa das falências em instituições com propriedades difusas e não pertencentes ao mercado acionário, como as cooperativas de crédito.

Outro engano que pode existir com relação à governança em cooperativas é pensar que não existe conflito decorrente de assimetria de poder entre os proprietários, uma vez que o princípio que rege a divisão de poder nessas instituições é: "um sócio, um voto", independente do capital. Apesar de não existir concentração de propriedade, há outro problema de comportamento igualmente danoso para a governança e que indiretamente gera assimetria de poder - o chamado "efeito carona (free rider)". Esse comportamento está diretamente relacionado ao sentimento de pertencimento e propriedade dos associados, se manifesta quando as pessoas sentem que sua contribuição individual representa pouco para o todo ou não Ihe permite capturar benefícios individuais.

Dadas as dificuldades em se quantificar esses riscos de comportamento, melhor denominados como incertezas de comportamento, a única maneira de reduzi-los é por meio de efetivos instrumentos de fiscalização e controle. O comportamento oportunista dos agentes somente é possível naquelas organizações em que os mecanismos de controle são falhos ou insuficientes (LAMB, s/d). 
No entanto, para criar uma estrutura de fiscalização e controle deve-se ter em conta que, qualquer mecanismo de controle resulta de um processo de arbitragem entre os efeitos dos comportamentos oportunistas dos agentes e os custos de controle que buscam alinhar os interesses dos dirigentes aos interesses dos proprietários - os chamados custos de agência, que de acordo com J ensen e Meckling (1976), são a soma dos seguintes custos:

a) Custos de criação e estruturação de contratos entre proprietários e dirigentes.

b) Custos de monitoramento das atividades dos dirigentes pelos proprietários (monitoring costs) - por exemplo, custos com auditorias.

c) Custos promovidos pelos próprios dirigentes para prestar contas aos proprietários (bonding costs) - relatórios e pareceres enviados aos proprietários.

d) Custos residuais (residual loss) - custos inerentes à divergência de interesses entre proprietários e dirigentes, decorrentes de escolhas não necessariamente ótimas.

Analisando esses custos no ambiente das cooperativas de crédito, pode-se acrescentar aos custos de monitoramento, os custos com controles internos (1) e com o Conselho Fiscal (2): o primeiro, a ser exercido pelos dirigentes para evitar os comportamentos oportunistas dentro da instituição; o segundo, se refere a um instrumento de fiscalização obrigatório no ambiente de cooperativas no Brasil. A Lei Cooperativa, 5.764/ 71, determina em seu art. 56 que:

A administração da sociedade será fiscalizada, assídua e minuciosamente, por um Conselho Fiscal, constituído de 3 (três) membros efetivos e 3 (três) suplentes, todos associados eleitos anualmente pela Assembléia Geral, sendo permitida apenas a reeleição de $1 / 3$ (um terço) dos seus componentes.

\section{METODOLOGIA DA PESQUISA}

0 artigo, além da revisão bibliográfica para buscar os fundamentos teóricos sobre governança em cooperativas, especialmente em relação aos instrumentos de fiscalização e controle, se baseou nos estudos e pesquisas realizados no âmbito do projeto estratégico Governança Cooperativa, do Banco Central do Brasil, nos anos de 2006 e 2007, na ordem a seguir apresentada:

Levantamento sobre os principais instrumentos de fiscalização e controle existente nos sistemas cooperativos: brasileiro, canadense, alemão, espanhol, colombiano, hondurenho e mexicano.

Pesquisa sobre os instrumentos de fiscalização e controle propostos pelos principais códigos de boas práticas de governança disponíveis na literatura: Recomendações da Comissão de Valores Mobiliários sobre governança corporativa (CVM, 2002); Código das Melhores Práticas de Governança Corporativa do Instituto Brasileiro de Governança (IBGC, 1999); Documento do Comitê de Supervisão Bancária do Bank for Internacional Settlements: Enhancing corporate governance for banking organisations (BIS, 2006).

Entrevista com os supervisores das cooperativas de crédito do Banco Central do Brasil, com o propósito de conhecer sua percepção sobre a governança nessas organizações - identificando pontos fortes e fracos. 
Entrevista com dirigentes de 34 cooperativas singulares e 11 cooperativas centraisl, com o propósito de entender a percepção dos dirigentes sobre as práticas de governança em suas instituições. Foi uma amostra dirigida, procurando cobrir todas as regiões do país, cooperativas de diferentes tipos e tamanhos.

Levantamento da legislação brasileira relacionada às cooperativas de crédito, bem como as resoluções do Conselho Monetário Nacional (CMN) e normas do Banco Central do Brasil.

Pesquisa com as cooperativas, realizada em setembro e outubro de 2007, por meio de questionário enviado à administração/dirigentes da cooperativa, com cerca de cem questões, aplicado via Internet, direcionado a todas as cooperativas de crédito singulares. Visou reconhecer as principais questões e problemas em relação à governança. 0 questionário foi respondido por 1199 , o que representa $86 \%$ do total de cooperativas de crédito singulares no país.

Pesquisa amostral com 420 associados. Tendo em vista que o associado, como agente proprietário, exerce papel importante no monitoramento da gestão e da fiscalização da cooperativa, foi realizada, em novembro e dezembro de 2007, uma pesquisa, por telefone, com associados de trinta cooperativas, sendo respondidas cerca de 30 questões, com 0 objetivo de investigar sua percepção em relação à cooperativa e aos dirigentes. A amostra selecionada cobriu todo o território nacional e os principais sistemas cooperativos (Unicred, Sicredi, Sicoob e Ancosol), bem como os diversos tipos de cooperativas - rural, de livre admissão, empresários, profissionais liberais, empregados de empresas públicas e privadas e cooperativas solidárias.

\section{INSTRUMENTOS DE CONTROLE E FISCALIZAÇÃO EM COOPERATIVAS DE CRÉDITO}

A potencial diferença de interesses entre dirigentes e proprietários e eventuais comportamentos oportunistas podem ser reduzidos por instrumentos de controle internos e externos (LAMB, s/d).

Os instrumentos internos de controle consistem no conj unto de arranjos sob a alçada da cooperativa que permitem reduzir a possibilidade de ações indevidas, assim entendidas tanto àquelas associadas a dolo, imperícia ou imprudência, quanto às ações bem intencionadas, mas que não estão plenamente aderentes ao desejo dos cooperados, principais interessados nos resultados da cooperativa. Esses instrumentos visam à supervisão do conjunto de contratos e acordos dentro da cooperativa, reforçando, principalmente, o monitoramento do conselho de administração sobre a gestão executiva e destes sobre o restante da organização. É importante destacar que os instrumentos de controle interno não são apenas aqueles formalmente constituídos - como, por exemplo, um sistema padronizado de controle, exercido por equipe especializada que, em muitos casos, faz parte da auditoria interna - mas, podem ser constituídos pelos agentes (partes interessadas) da cooperativa.

Entre os agentes que podem atuar como instrumentos de fiscalização e controle interno nas cooperativas de crédito destacam-se:

\footnotetext{
1 No Brasil, o segmento de cooperativas possui três níveis: as cooperativas singulares são consideradas de primeiro nível, as cooperativas centrais de segundo nível por serem formadas por cooperativas singulares, e as confederações são consideradas de terceiro nível, formadas por centrais.
} 
B Associados: pelo exercício ativo e bem informado dos seus direitos e deveres.

B Conselho Fiscal: por meio do exercício de uma fiscalização efetiva e independente.

ß Auditores internos: exercitando a profissão com qualidade e independência, adotando os padrões legais de auditoria e comunicando os resultados materialmente relevantes por meio de relatórios objetivos e inteligíveis, à gestão executiva, Conselho de Administração e Conselho Fiscal.

Empregados: pelo entendimento dos processos de controle aprovados pela gestão executiva e Conselho de Administração, a adoção dos valores éticos institucionais da cooperativa. Pela comunicação de preocupações relativas a práticas ilegais ou antiéticas, para essa finalidade, devem ser assegurados canais institucionais de comunicação e sigilo de informação.

Mas, embora a responsabilidade principal pelo bom funcionamento dos instrumentos de controle e fiscalização seja do Conselho de Administração e da gestão executiva, esses podem falhar se interesses oportunistas dos conselheiros estiverem alinhados com os dos gestores, visando obter benefícios em detrimento dos interesses dos demais associados. Nesse sentido, há necessidade de se estabelecer também controles externos, arranjos ou dinâmicas existentes fora do âmbito da organização, que atuam limitando os comportamentos oportunistas dos dirigentes (Conselho de Administração e gestão executiva).

Em sociedades por ações, os mecanismos do mercado regulam e disciplinam sua governança: as flutuações nos valores das ações sinalizam verde, amarelo ou vermelho, e fusões e propostas de aquisições convidam equipes de gerenciamento de baixa performance a saírem. As cooperativas de crédito, diferentemente dos bancos, por não possuírem títulos no mercado secundário, não estão suj eitas à avaliação dos investidores e não gozam do efeito disciplinador desse mercado.

Mas, um poderoso instrumento de fiscalização e controle externo e, portanto, provedor de qualidade de governança é a integração de cooperativas individuais em rede (PARADIS, 2001). Nesse sentido, os seguintes agentes atuam como instrumentos de fiscalização e controle nas cooperativas de crédito:

- Órgãos reguladores e fiscalizadores do sistema financeiro: ao normatizar e fiscalizar o segmento, o Banco Central estimula a criação de padrões desejáveis de comportamentos. Por ter como missão a segurança sistêmica, articula também os diversos mecanismos externos de monitoramento visando melhorar sua efetividade.

- Auditores externos: são profissionais suj eitos às normas e à supervisão da Comissão de Valores Mobiliários e respondem judicialmente por seus pareceres e relatórios, tanto na esfera civil quanto na criminal. Isso tende a tornar o trabalho da auditoria externa um instrumento eficaz de fiscalização e controle dos registros contábeis.

- Fundos garantidores de crédito: visam assegurar determinado valor dos depositantes, no caso de quebra das cooperativas; eles podem e devem supervisionar essas instituições, a exemplo do que ocorre nos EUA, onde o Federal Deposit Insurance Corporation (FDIC) também tem função de supervisão bancária.

- Demais agentes que tenham interesses na cooperativa: por exemplo, instituições privadas e governamentais fornecedoras de recursos.

É importante destacar, em relação aos instrumentos de fiscalização e controle, que a assimetria de informação entre os agentes é um grande estimulador de comportamentos oportunistas. Portanto, a eficiência e a eficácia de qualquer instrumento de fiscalização e o controle, tanto interno quanto externo, estão fortemente associadas à quantidade e qualidade das informações disponibilizadas aos agentes responsáveis pela função. 
Dessa forma, os instrumentos propostos a seguir são norteados pelo princípio da transparência, tanto na relação entre os agentes/atores quanto na divulgação das informações.

\subsection{Analisando as formas de fiscalização e controle em cooperativas de crédito no brasil}

Atores responsáveis pelo monitoramento, controle e fiscalização das cooperativas de crédito - os associados, a auditoria interna e externa, o conselho fiscal e as demais instituições que compõem o sistema cooperativo - podem agir de modo a obter mais segurança e fortalecer o sistema cooperativista de crédito no Brasil. Para tanto, o objetivo desse tópico é apresentar análise, baseada nos resultados dos estudos e pesquisas, sobre as possibilidades desses atores atuarem como efetivos instrumentos de fiscalização e controle. Deve ser ressaltado que outros atores/ órgãos também podem e devem cumprir esse papel, como por exemplo, o Conselho de Administração, e que as propostas não pretendem ser exaustivas - ou seja, existem outras possibilidades, aqui não tratadas.

Associados: o associado, como proprietário, é a parte mais interessada nos negócios da cooperativa. Portanto, a administração tem o dever de criar instrumentos para assegurar sua participação e, assim, evitar o chamado efeito carona (free rider). De acordo com os dados da pesquisa, na última assembléia geral ordinária da cooperativa, em $65 \%$ das cooperativas, menos de $15 \%$ dos associados assinaram a lista de presença, configurando uma baixa participação, portanto. Os principais motivos apontados pelos dirigentes/ cooperativas para essa baixa participação são a "confiança dos associados na administração da cooperativa" (32,2\%) e a "falta de conhecimento do associado a respeito da sua importância na assembléia" (27\%).

Todavia, na visão dos associados em relação à sua baixa participação, as principais motivações estão relacionadas a fatores pessoais (38,9\% das respostas), sendo: $12,9 \%$ afirmando que "não faz diferença ir" à assembléia; $12,4 \%$ que 0 "tempo gasto é muito grande"; $10 \%$ que há "dificuldade de deslocamento"; e somente $3 \%$ apontam que o motivo é a "confiança na administração da cooperativa" - embora 85,5\% afirmem que confiam totalmente nos dirigentes. Mais da metade do associados (51\%) respondeu pela existência de "outros" motivos. A análise desses "outros" motivos mostra que $55,9 \%$ são relacionados a fatores pessoais, tais como falta de tempo $(35,9 \%)$, falta de interesse $(12,2 \%)$ e horário, data ou distância incompatível (7,7\%). Entre os motivos apontados para a baixa participação, que se referem à percepção do associado sobre as ações da cooperativa, está a falta de divulgação da realização da assembléia, com 8,8\% das respostas.

Essas respostas mostram a fragilidade dos sistemas internos de controle e monitoramento por parte dos associados, evidenciando o chamado "efeito carona", pelo qual o associado pondera a importância de participar frente aos benefícios que pode obter pela melhoria advinda dessa supervisão. Alguns entendem que não há espaço para melhorar a gestão e outros simplesmente consideram sem importância sua presença. Ao não participar, torna-se menos consciente de seu papel e interpreta como cada vez menos produtiva sua participação, gerando um ciclo que enfraquece o controle interno pelos associados.

A falta de consciência de seus direitos e deveres é outro fator que contribui para fragilizar 0 sistema de controle por parte dos associados: 50,6\% dos associados entrevistados nunca leu o estatuto da cooperativa; $23,9 \%$ não conhecem seus direitos e deveres e $41,3 \%$ os conhecem apenas parcialmente. 
Além disso, a ausência de mecanismos formais que permitam aos associados ou delegados incluírem itens nas pautas das assembléias também contribui para tornar 0 controle e a fiscalização ineficientes: $62,72 \%$ das cooperativas da amostra indicam que não possuem esse tipo de mecanismo. E mais, das cooperativas que dispõem desse mecanismo $(36,36 \%$ ), em apenas $6,01 \%$ houve algum caso de inclusão de item pelos associados na última assembléia.

Essa falta de controle dos associados é preocupante uma vez que nas cooperativas de crédito, como os usuários dos serviços são também os donos do negócio, eles assumem riscos e responsabilidades que extrapolam as de um simples usuário de serviços financeiros. Em decorrência da previsão expressa no art. 1.095 do Código Civil de 2002 e nos arts. 89 e 80 da Lei 5.764/1971, o sócio de uma cooperativa passa a responder não somente pela parcela de sua contribuição ao capital social, correspondente às quotas por ele integralizadas, mas também pelos prejuízos porventura verificados, na proporção das operações que tiver realizado. 0 § 20, artigo 1.095, do Código Civil também se refere a uma responsabilidade ilimitada dos sócios: "É ilimitada a responsabilidade na cooperativa em que o sócio responde solidária e ilimitadamente pelas obrigações sociais". Ainda, o art. 36 da Lei 5.764/1971 afirma: "A responsabilidade do associado perante terceiros, por compromissos da sociedade, perdura para os demitidos, eliminados ou excluídos até quando aprovadas as contas do exercício em que se deu o desligamento" (BRASIL, 1971).

Para associados empregados, o art. 31 da Lei 5.764/ 1971 traz a seguinte ressalva: "O associado que aceitar e estabelecer relação empregatícia com a cooperativa perde o direito de votar e ser votado, até que sejam aprovadas as contas do exercício em que deixou o emprego" (BRASIL, 1971). Nesse caso, continua como associado, respondendo somente limitadamente à parcela de sua contribuição ao capital social.

Apesar dessa responsabilidade, os associados se mostram pouco conscientes da importância de exercerem um efetivo controle sobre os negócios das cooperativas. Somente $8,3 \%$ das respostas dos dirigentes/ cooperativas aos fatores que melhor explicam a motivação dos cooperados a comparecerem às assembléias aponta a "comunicação do rateio de perdas e/ ou despesas". Dado o nível de responsabilidade dos associados, essa deveria ser, pela lógica, a principal motivação para o comparecimento.

Diante dos resultados das pesquisas e da responsabilidade que a legislação brasileira imputa aos associados, propõe-se que a administração das cooperativas assegure canais institucionais para que eles exerçam efetivamente seu direito-dever de fiscalizar e controlar os negócios da cooperativa, uma vez que em cooperativas a responsabilidade legal dos sócios pode ser limitada ou ilimitada. A administração deve criar meios para que todos os associados tenham ciência de seus direitos e deveres legais e estatutários, especialmente em casos de perda e/ ou prejuízo.

Auditorias: uma das contribuições do trabalho de auditoria é reduzir a assimetria de informação - fator que favorece o comportamento oportunista dos responsáveis pela gestão executiva. Existe assimetria de informação entre Conselho Fiscal, Conselho de Administração e gestão executiva. Os gestores tendem a conhecer mais os negócios da cooperativa do que os responsáveis pela fiscalização e monitoramento, conseqüentemente podem omitir informações em seu benefício. A auditoria pode reduzir essa assimetria ao confrontar a veracidade dos dados informados nos relatórios gerenciais e econômicofinanceiros enviados ao Conselho Fiscal e Conselho de Administração.

Outra contribuição da auditoria é na mitigação do risco operacional, também conhecido como risco de processo - riscos de falhas humanas, defeito de equipamento ou processo e risco de fraude e/ ou omissão. Especialmente em cooperativas pequenas, onde não há controles informatizados, o gerenciamento desse risco depende muito da auditoria, 
que pode, com independência, relatar irregularidades e fatos relevantes ao Conselho de Administração e ao Conselho Fiscal.

De acordo com as respostas das cooperativas, 74,48\% não possuem estrutura de auditoria interna. Parte disso é explicada pela transferência desse serviço às cooperativas centrais. Nas que possuem suas próprias estruturas de auditoria interna, esta não está subordinada exclusivamente ao Conselho de Administração - apenas 17,18\% das respostas das cooperativas indicaram o Conselho de Administração como o responsável pela definição das diretrizes e atuação da auditoria. Se não é o Conselho de Administração quem define as diretrizes e a atuação da auditoria, o trabalho pode ficar comprometido e sem a independência necessária.

Para ser um importante instrumento de fiscalização e controle, a auditoria interna precisa ter independência e, para assegurá-la, é necessário estabelecer regras e procedimentos garantindo a qualidade do trabalho. Diante dessa constatação, recomendase que: (i) a auditoria interna seja subordinada diretamente ao Conselho de Administração; (ii) a contratação dos auditores internos também esteja sob a responsabilidade desse conselho; (iii) os relatórios da auditoria interna sejam encaminhados ao Conselho de Administração, Conselho Fiscal e aos responsáveis pela gestão executiva; e (iv) os normativos da cooperativa contenham dispositivos que assegurem a independência da auditoria interna.

Quanto à auditoria externa, para ser eficaz, também precisa de métodos ou/ e regras que garantam sua independência. A cooperativa deve adotar regras que reduzam o risco de os auditores omitirem irregularidades ou fatos relevantes, por exemplo. Ainda, a cooperativa pode adotar a rotatividade obrigatória de auditores, bem como outras regras e limites pertinentes e permitidos por lei.

Dado o risco de se contratar uma auditoria apenas para cumprimento legal e sem a independência necessária, é aconselhável que a contratação da auditoria externa também seja aprovada pelo Conselho de Administração e que os normativos da cooperativa contenham dispositivos que assegurem sua independência. Todavia, e como exemplo de que isso pode não estar acontecendo, apenas 37,11\% das cooperativas da amostra indicaram existir mecanismo formalizado que impeça que a empresa de auditoria externa contratada tenha vínculos com membros ou com parentes de membros dos órgãos estatutários da cooperativa, o que pode evidenciar a baixa preocupação com 0 estabelecimento de regras que garantam sua independência.

Conselho Fiscal: o Conselho Fiscal é um dos mais importantes instrumentos de fiscalização e controle, uma vez que ele é subordinado exclusivamente à Assembléia Geral e, portanto, está fora do conflito de interesse entre administradores - Conselho de Administração e gestão executiva.

Apesar de sua relevância, o Conselho Fiscal é visto por muitos, de forma equivocada, como um órgão que deve se ater apenas a assuntos de natureza contábil, por meio da análise de balancetes trimestrais e das demonstrações financeiras do exercício social, emitindo sobre essas últimas sua opinião. No entanto, a primeira e a mais importante competência do Conselho Fiscal é a de "fiscalizar os atos dos administradores e verificar o cumprimento de seus deveres legais e estatutários", entendendo como atos dos administradores qualquer ato de gestão praticado, seja pelo administrador ou, por delegação de autoridade, por qualquer funcionário da cooperativa.

Entretanto, as atribuições e a importância do Conselho Fiscal são desconhecidas de quase todas as partes, a começar pelos associados: apenas 20,2\% responderam que conhecem totalmente as atribuições desse conselho; outros $13 \%$ responderam que conhecem parcialmente, enquanto a maioria, 54,3\% desconhecem tais atribuições. Ainda 
assim, 77\% dos cooperados que responderam à pesquisa consideram que o Conselho Fiscal é eficaz e preocupado com a solidez da cooperativa.

Sobre a independência do Conselho Fiscal, 62,6\% dos cooperados consideram sua atuação totalmente independente da Administração, mas, por outro lado, segundo os dirigentes/ cooperativas, a principal motivação para a candidatura ao Conselho Fiscal é a indicação/ convite de diretores ou conselheiros $(58,47 \%)$. Esse fato evidencia uma situação de baixa independência dos conselheiros fiscais frente aos dirigentes, o que contribui para reforçar as percepções obtidas na fase das entrevistas, quais sejam, que o conselho fiscal é percebido muitas vezes como um mecanismo de entrada de futuros dirigentes nas cooperativas, desvirtuando suas funções e fragilizando as estruturas de controle e fiscalização.

O escopo de fiscalização do conselheiro fiscal deve ser o mais amplo possível, em virtude das responsabilidades legais que Ihe são impostas, em caso de má conduta. 0 artigo 1.070 do Novo Código Civil e o artigo 53 da Lei 5.764/1971 estabelecem que os componentes da administração e do Conselho Fiscal se equiparam aos administradores das sociedades anônimas para ef eito de responsabilidade criminal, podendo responder às ações oriundas de cooperados ou terceiros.

De igual modo, a Lei 6.404/ 1976 amplia a atuação do Conselho Fiscal ao estabelecer, como de sua competência, opinar sobre as propostas dos órgãos da administração, a serem submetidas à assembléia-geral, relativas a modificação do capital social, planos de investimento ou orçamentos de capital, transformação, incorporação, fusão ou cisão.

Para o bom exercício de sua função fiscalizadora, o conselheiro fiscal precisa de autonomia para acessar informações pertinentes à sua atribuição, podendo, em analogia ao inciso IV do artigo 163 da Lei 6.404/ 1976 e do inciso IV do artigo 1.069 do Novo Código Civil, denunciar aos órgãos de administração os erros, fraudes ou crimes que descobrirem e sugerir providências úteis à companhia. Caso os órgãos de administração não tomem as providências necessárias, ou estejam dificultando ou impedindo esse acesso, pode o Conselho Fiscal, convocar uma assembléia-geral para denunciar tais fatos.

Contudo, ao criarem seus instrumentos de controle e fiscalização, as cooperativas devem considerar que esses resultam de um processo de arbitragem entre os custos/ perdas provocados pelos comportamentos oportunistas dos diversos agentes envolvidos com a cooperativa e os custos de controle desses comportamentos. Assim, o Conselho Fiscal, ao solicitar informações, sempre deve ponderar o custo e o benefício dessa informação, bem como a capacidade financeira da cooperativa.

Em relação ao acesso às informações, a quase totalidade das respostas $(97,25 \%)$ dos dirigentes/cooperativas indicou que os membros do Conselho Fiscal têm acesso, individualmente, a todos documentos e informações necessários ao exercício de sua função, o que representa um aspecto importante e necessário na independência desse conselho. Mas, por outro lado, $48,12 \%$ dos dirigentes/cooperativas afirmam que não encaminham aos membros do Conselho Fiscal, com antecedência, os documentos a serem examinados em suas reuniões, o que gera um ponto crítico e que exige melhoria, pois não parece possível analisar, com o devido cuidado, as informações necessárias para 0 desempenho de suas funções se elas estiverem disponíveis apenas no momento da reunião.

Ainda em relação às informações prestadas ao Conselho Fiscal, 85,90\% dos dirigentes/ cooperativas responderam que existe processo regular de apresentação da cooperativa aos novos conselheiros fiscais, contemplando tanto informações internas quanto externas relacionadas ao exercício de suas funções. É fundamental que o Conselho Fiscal, principalmente aqueles em primeiro mandato, sejam devidamente apresentados aos principais números e informações da cooperativa e também às responsabilidades inerentes a sua função. Neste ponto, cabe destacar a necessidade de dar conhecimento a esses 
consel heiros de suas responsabilidades legais individuais, ou seja, em caso de problemas deve tomar ação independentemente da ação dos demais membros do conselho, caso julgue necessário.

Considerando a importância do Conselho Fiscal como instrumento de fiscalização e controle e o escopo do seu trabalho, algumas recomendações são necessárias. Como exemplo, o Conselho Fiscal pode requerer à administração os recursos humanos, materiais e financeiros para consecução de suas funções; e, a pedido de qualquer dos seus membros, poderá solicitar aos órgãos de administração esclarecimentos ou informações, desde que relativos à sua função fiscalizadora, bem como a elaboração de demonstrações financeiras ou contábeis especiais e solicitar aos auditores externos e internos esclarecimentos ou informações e a apuração de fatos específicos. Ainda, o Conselho Fiscal pode convocar membros do Conselho de Administração, da gestão executiva ou do quadro funcional, bem como convidar associados, a fim de prestar esclarecimentos.

A eficácia da atuação do Conselho Fiscal depende de sua independência e imparcialidade na realização dos trabalhos, podendo o estatuto da cooperativa e/ ou o regimento do conselho estabelecer regras para isso, ponderando as caracteríesticas da cooperativa e os limites da lei. A legislação estabeleceu algumas regras para assegurar a independência desse conselho - §10 do artigo 1.066 do Novo Código Civil.

Assim, recomenda-se que os membros do Conselho Fiscal não devam ter negócios com a cooperativa além daqueles realizados na condição de associados, nem devem ser empregados de entidade e/ ou empresa que esteja oferecendo algum serviço ou produto à cooperativa e também não devem ser cônjuges ou parentes até segundo grau de membros da diretoria executiva ou de gerentes da cooperativa.

0 trabalho do Conselho Fiscal deve ser sistematizado e possuir padrão mínimo para evitar que o conselho deixe de executar trabalhos básicos que permitam identificar os problemas e situações mais prováveis de ocorrer em uma cooperativa de crédito. Para isso, recomenda-se que o Conselho Fiscal tenha regimento interno que discipline 0 funcionamento do órgão e o planejamento das atividades, contendo, no mínimo, o plano de trabalho e a forma de divulgação dos resultados de sua atuação, que poderão ser por pareceres, opiniões, recomendações e o encaminhamento de denúncias recebidas. 0 relatório de trabalho do Conselho Fiscal deve expressar a atuação do órgão, abordando os aspectos relevantes constatados em suas análises e fazendo referência às recomendações dos auditores.

Embora o Conselho Fiscal e as auditorias sejam órgãos pertencentes à estrutura de fiscalização e controle, suas funções dentro da cooperativa são distintas e complementares. As auditorias devem prestar contas tanto ao Conselho de Administração quanto ao Conselho Fiscal. Portanto, o Conselho Fiscal não só pode, mas deve usar os relatórios, pareceres e recomendações das auditorias, interna e externa, como fonte de informação para realização e conclusão de seus trabalhos, bem como reunir-se com a auditoria de forma a buscar a colaboração mútua.

Em relação à capacitação técnica dos conselheiros fiscais, 31,28\% das respostas de dirigentes/ cooperativas informaram que não há pré-requisito de capacitação técnica para membros do Conselho Fiscal. A compreensão expressa nesta questão é que, diferentemente da administração, que no caso das cooperativas é um órgão de alta representatividade política, no Conselho Fiscal deve-se predominar a capacidade técnica dos seus membros. As respostas indicaram que nesse aspecto há necessidade de melhoria.

Com relação ao rigor e freqüência da fiscalização, de acordo com o art. 56 da Lei 5.764/1971, as cooperativas devem ser fiscalizadas assídua e minuciosamente. Mas, uma fiscalização com esse nível de profundidade só é possível com pessoas qualificadas, que devem ser, se possível, adequadamente remuneradas. 
Entretanto, mais de $40 \%$ das respostas de dirigentes/cooperativas afirmaram não existir qualquer remuneração pela função de conselheiro fiscal. Reconhecendo que essa remuneração deve estar vinculada ao porte e à capacidade financeira de cada cooperativa, entende-se que o risco, responsabilidades e demandas inerentes ao cargo devem ter justa remuneração. Sua falta pode ensejar tanto ações voluntaristas - bem intencionadas ou eventualmente na expectativa de retornos futuros - quanto desestimular uma atuação mais efetiva desse conselho e inibir as cobranças sobre sua atuação, sob o argumento que executa um trabalho não remunerado. Portanto, a recomendação é que a remuneração dos membros do Conselho Fiscal deve ser equivalente à dos membros do Conselho de Administração.

Tendo em vista que o Conselho Fiscal tem a atribuição específica de fiscalizar e a razão de sua existência é dar mais segurança aos sócios, a cooperativa deve adotar canais institucionais para que os associados possam acompanhar e cobrar o trabalho desse conselho. $E$, uma vez que os conselheiros devem prestar contas aos associados e à Assembléia Geral, é recomendável, por exemplo, que pelo menos um dos membros do conselho fiscal compareça às reuniões da Assembléia Geral para responder aos pedidos de informações formulados pelos associados.

Organização sistêmica: a estrutura em rede é um importante instrumento de controle externo para as cooperativas de crédito, uma vez que estas não estão sujeitas ao controle exercido pelos investidores em mercado de capitais. Para compensar a falta desse controle, as cooperativas precisam de mais supervisão e regulação que as demais instituições financeiras. Se elas estiverem vinculadas a um sistema cooperativista ou a uma cooperativa central que possui mecanismos de auto-regulação e supervisão próprios, isso complementaria a estrutura de controle e supervisão, contribuindo para a boa governança dessas instituições.

As confederações ou sistemas organizados, ao cumprirem suas próprias responsabilidades relativas à governança, lideram a conciliação das estratégias individuais de governança de suas filiadas e das cooperativas singulares que as compõem. Das 1199 cooperativas que responderam ao questionário, apenas 223 estão sem vínculo com algum sistema. Vale lembrar, entretanto, que a atuação da confederação ou sistema organizado não isenta a responsabilidade das centrais e singulares pela efetividade individual das boas práticas de governança.

Quanto à relação entre as instituições em um sistema cooperativo, recomenda-se que os sistemas organizados estabeleçam e divulguem a política de relacionamento entre suas filiadas, buscando mitigar conflitos de interesses entre centrais e, ainda, entre essas e as respectivas singulares.

Os cargos executivos em cooperativas singulares, centrais e confederações não devem ser ocupados pela mesma pessoa, a fim de assegurar a independência dos trabalhos dessas centrais e confederações, especialmente de supervisão. Em 36\% das cooperativas pelo menos um de seus membros de órgãos estatutários são também membros de órgãos estatutários na central ou confederação. A acumulação de cargos, principalmente os de natureza executiva, pode criar situação conflituosa, uma vez que as centrais têm como atribuição a supervisão das singulares, além de reduzir a dedicação desse membro na singular quando passa a assumir função na central e/ ou na confederação.

Ainda, é aconselhável que as cooperativas centrais produzam e divulguem classificação/ indicadores de suas cooperativas filiadas - tais como custos administrativos frente à receita, nível de exposição a riscos e índices de inadimplência, dentre outros de interesse dos cooperados. Esses indicadores podem servir como fonte de referência para as diversas partes interessadas - associados, funcionários, comunidade, órgãos de supervisão e controle, instituições financeiras fornecedoras de recursos. 


\section{CONSIDERAÇÕES FINAIS}

O sistema cooperativista de crédito brasileiro, entre 1997 e 2007, teve pouco crescimento em termos de quantidade de cooperativas, passando de 1.120 para 1.423 cooperativas. Por outro lado, sua participação nos principais agregados do sistema financeiro teve aumento expressivo, de $1,4 \%$ do patrimônio líquido para 2,4\% Outros indicadores mostram aumento relativo: operações de crédito aumentaram de 0,7 para 2,3\% depósitos e ativos totais, de 0,3\% para 1,5\% Em relação ao número de associados atendidos pelas cooperativas de crédito, estes passaram de 1,4 milhões em 2001 para 2,8 milhões em 2006, atingindo um total de 3,5 milhões em 2007.

Para manter o espaço conquistado ou ampliar sua fatia no mercado financeiro, o segmento de crédito cooperativo tem como desafio melhorar suas práticas de governança, especialmente adotando instrumentos de fiscalização e controle mais eficientes. A ampliação da base de associados e das fontes de capacitação, conseqüências naturais do crescimento, aumentam os problemas de agência e o risco moral; e a mitigação e 0 controle desses riscos só podem ocorrer com bons mecanismos de controles internos e externos. Além desses aspectos, o cooperativismo tem o desafio de enfrentar um novo ambiente macroeconômico - redução de taxas básicas de juro, redução no spread, aumento da concorrência do crédito de varejo, seu principal nicho de mercado.

Apesar dos desafios, o ambiente institucional é favorável ao crescimento. Além da Lei 5.764/ 1971, que já instituiu importantes instrumentos de fiscalização e controle, tanto internos quanto externos, $0 \mathrm{CMN}$ e o Banco Central, atentos ao crescimento e às necessidades do segmento, promoveram, no limite de suas competências, mudanças institucionais significativas tanto na regulação quanto na supervisão do sistema cooperativista de crédito. Nesse sentido, com o intuito de melhorar a supervisão das cooperativas de crédito, foi criada área específica para a supervisão dessas cooperativas e do segmento não bancário no Banco Central, com o intuito de ter um departamento mais voltado para as peculiaridades desses segmentos.

Em relação à regulação, a Resolução 3.442/2007, do CMN contém dispositivos que exigem adoção de instrumentos de fiscalização e controle mais rigorosos e incentivos para as cooperativas se integrarem em sistemas de rede.

Os resultados da pesquisa, embora evidenciem diversos aspectos da governança que carecem de melhorias, também mostra aspectos positivos que contribuirão para que o cooperativismo vença os novos desafios e o aumento de sua participação no mercado financeiro de forma sustentada.

\section{REFERÊNCIAS}

\section{BIS. BANK for International Settlements. Enchancing corporate governance for banking organizations. Fev. 2006. Disponível em}

<http:// www. bis.org/ publ/ bcbs122. pdf>. Acesso em: 25 Oct 2006.

BRASIL. Lei n. 5764, de 16 de dezembro de 1971. Define a política nacional de cooperativismo, institui o regime jurídico das sociedades cooperativas e dá outras providências. Disponível em: 〈http:// www. senado. gov.br>. Acesso em: 05 mar 06. 
CVM. Comissão de Valores Mobiliários. Recomendações da CVM sobre Governança Corporativa. Junho 2002.

Disponível

em

<http:/ / www. ecgi. org/ codes/ documents/ cartilha. pdf. >. Acesso em: 25 Oct 2006.

DESROCHERS, Martin \& FIRCHER, Klaus P. Corporate Governance and Depository Institutions Failure: The Case of an Emerging Market Economy. July 2002. Social Science Research Network. Disponível no site:

<http:/ / papers. ssrn. com/ sol3/ papers. cfm?abstract id=345980>. Acesso em 30 Abr 2007.

IBGC. Instituto Brasileiro de Governança Corporativa. Código das Melhores Práticas de Governança. 1999. Disponível em http:// www.ibgc.org.br/CodigoMelhoresPraticas.aspx. Acesso em: 23 Mai 2007.

J ENSEN, Michael C., MECKLING, William H. Theory of the firm: managerial behavior, agency costs and ownership structure. J ournal of Financial Economics, v.3, n. 4, p.305360, Oct. 1976.

KREPS, David (1990). A Course in Microeconomic Theory. Princeton: Princeton University Press.

LAMB, Roberto. Governance corporative: arena e contexto. Universidade Federal do Rio Grande do Sul, s.d., mimeo.

LETHBRIDGE, Eric. Governança corporativa. Revista do BNDES, n.8, dez. 1997.

OCDE. Organização para a Cooperação e Desenvolvimento Econômico. Disponível em বhttp:// www.oecd.org>. Acesso em: 27 jun 07.

PARADIS, Ghislain. Governance in Savings and Credit Cooperatives. Notes for a presentation - Fourth Seminar on New Development Finance - September 7, 2001 disponível no site:

<http:// www.did.qc.ca/ documents/ GPA Frankfurt SEP01. pdf>. Acesso em 27 jul 2007

WILLIAMSON, Oliver E. The Economic Institutions of Capitalism. The Free Press. New York. 1987.

\section{ENDEREÇO DOS AUTORES}

BANCO CENTRAL DO BRASIL

Brasília - DF 